\title{
A FLEXIBILIDADE ORGANIZACIONAL COMO FATOR ESTRATÉGICO PARA A OBTENÇÃO DE VANTAGEM COMPETITIVA: UM ESTUDO NAS PEQUENAS INDÚSTRIAS METALÚRGICAS DA REGIÃO DE OSASCO (SP)
}

ORGANIZATIONAL FLEXIBILITY AS A STRATEGIC FACTOR FOR OBTAINING COMPETITIVE ADVANTAGE: A STUDY IN SMALL METAL INDUSTRIES IN THE REGION OF OSASCO (SP)

Antonio Fernandes Barreto

Mestre em Administraçäo pela FACCAMP (Faculdade Campo Limpo Paulista) -

Linha de Pesquisa Gestäo de Micro e Pequenas Empresas

\section{Hamilton Pozo}

Professor do Programa de Mestrado Profissionalizante em Administração da Faculdade Campo Limpo Paulista - FACCAMP
Data de envio: 28/07/2011

Data de aceitação: 04/08/2011

\section{RESUMO}

O objetivo da presente pesquisa foi investigar se a flexibilidade organizacional pode fornecer competitividade às micro e pequenas empresas (MPEs), em especial às pequenas indústrias metalúrgicas, gerando assim uma vantagem competitiva. Foi utilizado como instrumento de pesquisa um questionário com escala de concordância tipo Likert, compreendendo o modelo organizacional flexível, desenvolvido por Mendes (2002) e composto pelos seguintes fatores: organização do trabalho; gestão de pessoas e processo decisório; e foco no cliente. A pesquisa se caracteriza como de natureza exploratória, cujos métodos empregados são o qualitativo e o quantitativo na avaliação do modelo utilizado. Os resultados foram analisados com a aplicação de estatística não paramétrica pela análise das medianas e comparação de dados, obtendo-se, como resultado, a concordância com o modelo organizacional flexível e a competitividade demonstrada pela longevidade encontrada na amostra pesquisada.

Palavras-chave: flexibilidade organizacional; pequenas indústrias; modelo organizacional flexível.

\section{ABSTRACT}

The objective of this research was to investigate whether organizational flexibility can provide competitiveness of micro and small business (MSBs), especially small metalworking industries, thus creating a competitive advantage. It was used as a research tool questionnaire with Likert type scale of agreement, including the flexible organizational model, consisting of the factors: work organization, personnel management and decision making, and customer focus developed by Mendes (2002). The research is characterized exploratory in nature, whose methods are used in the qualitative and quantitative evaluation of the model. The results were analyzed by applying non-parametric statistical analysis of the median and comparing data. As result, the agreement with the flexible organizational model demonstrated the longevity and competitiveness found in the sample studied.

Keywords: organizational flexibility; small industries; flexible organizational model.

Endereços dos autores: 


\section{INTRODUÇÃO}

No mercado atual, encontra-se um público cada vez mais exigente por alternativas de consumo, uma nova cor, uma nova funcionalidade de um produto, um serviço inovador, sem oferecer garantia de continuidade de consumo ao seu fornecedor. E, por uma pequena fração de tempo, uma determinada empresa detém uma fatia de mercado e um produto inovador. Porém, o sucesso pode ser repentino, pois logo outras empresas rapidamente disponibilizam aquele produto com melhorias, gerando um círculo natural de inovação e criatividade, o que fomenta cada vez mais ações empreendedoras em um mercado competitivo. A esse respeito, Porter (2004: 3) relatou: "A essência da formulação de uma estratégia competitiva é relacionar uma companhia ao seu meio ambiente".

Esta pesquisa está concentrada nas micro e pequenas empresas - MPEs, em especial na pequena indústria localizada na região de Osasco, na Grande São Paulo.

A pequena indústria é caracterizada por duas variáveis: a primeira refere-se ao número de empregados, devendo possuir de 20 a 99 trabalhadores a ela vinculados; e a segunda, pela receita bruta anual, conforme prevê a Lei Geral da Micro e Pequena Empresa, promulgada em 14 de dezembro de 2006, que definiu microempresa aquela que auferir receita bruta igual ou inferior a $R \$ 240$ mil reais e empresa de pequeno porte, aquela que auferir receita bruta anual igual ou inferior a $\mathrm{R} \$ 2,4$ milhões.

A flexibilidade organizacional é apontada por alguns autores como meio para inovação e competitividade (Imparato \& Harari, 1997; Tenório, 2002; Levy, 1992; MintzBerg, 2009; Ansoff \& McDonnell, 1993), podendo auxiliar as MPEs a melhorar seu desempenho e aumentar sua competitividade.

O objetivo principal desta pesquisa é demonstrar que a flexibilidade organizacional é um diferencial estratégico para a pequena indústria, gerando, assim, um modelo de gestão que possa proporcionar vantagem competitiva sustentável, além de sobrevivência e longevidade.

Um estudo realizado por Mendes (2002) trouxe um instrumento que será utilizado para medir o grau flexibilidade em uma organização. Trata-se de um questionário que aborda fatores importantes para uma organização flexível, como (1) organização do trabalho; (2) gestão de pessoas e processo decisório; (3) foco no cliente. O instrumento utilizado por Mendes (2002) foi adaptado e aplicado ao principal gestor das micro e pequenas empresas, em especial as pequenas indústrias, com o objetivo de medir o grau de flexibilidade de sua organização.

Esta pesquisa estuda as pequenas indústrias metalúrgicas - compostas pela faixa de 20 a 99 funcionários - que estão localizadas na região de Osasco, compreendida por 11 municípios e 449 empresas. A pesquisa obteve a participação de 20 pequenas indústrias, representando $4,67 \%$ da população consultada.

O objetivo da pesquisa foi conhecer o grau de flexibilidade organizacional utilizado nesta população, por meio das respostas dos gestores com a aplicação de um questionário empregando uma escala de concordância do tipo likert de 6 pontos, agrupados por características da empresa e de seu principal gestor. Os dados foram analisados por comparação das medianas e aplicação do coeficiente Alpha de Cronbach, que avaliou o modelo organizacional flexível a partir dos fatores que o compõem. Finalmente, o trabalho foi complementado pelo coeficiente de correlação de Pearson, que verifica a correlação entre o item pesquisado e o total obtido na pesquisa.

A Itália pós-guerra estava dividida economicamente entre o norte, que prosperava e se desenvolvia devido ao seu potencial industrial, e o sul, predominantemente agrícola, que constantemente era atacado por povos estrangeiros. As pequenas e médias empresas foram importantes atores na diminuição das desigualdades regionais, devido ao modelo de desenvolvimento italiano, que favoreceu o acesso a linhas de financiamento, reduziu impostos, dispensou pagamentos relativos à parte previdenciária e implantou auxílio financeiro a empresas criadas em áreas menos desenvolvidas (Souza Neto, 2006).

Pretende-se, com este estudo, contribuir com a melhoria da qualidade da gestão da pequena empresa, observando aspectos de competitividade e fornecendo informações para melhoria de sua gestão e desempenho, visto que as pequenas indústrias exercem importante papel na composição do ramo de mercado integrado pelas micro e pequenas empresas, que respondem por $98 \%$ das empresas, $67 \%$ 
das ocupações e $20 \%$ do PIB $^{1}$ brasileiro. A pesquisa 10 anos de monitoramento da sobrevivência e mortalidade de empresas, realizada pelo Sebrae em 2008, demonstrou que $27 \%$ das empresas paulistas ainda fecham em seu primeiro ano de atividade, indicando que um dos principais motivos para tanto diz respeito à gestão empresarial, que não evidenciou sinais de melhoria no período monitorado (SEBRAE-SP, 2008).

\section{REFERENCIAL TEÓRICO}

O ambiente externo, como o mercado e a competitividade, contribui para a evolução estrutural das empresas. Segundo Ansoff \& McDonnell (1993: 357), "um estudo da evolução das empresas privadas americanas mostra que, além das pressões ambientais, sempre houve um esforço interno para fazer as coisas de forma melhor e mais eficiente".

As organizações militares de Frederico, o Grande, da Prússia, que reinou entre 1740 e 1786, serviram de referência como as primeiras estruturas organizacionais desenvolvidas em torno das organizações burocráticas que possuíam um modo de pensar mecanicista, caracterizado por possuir atividades rotineiras, eficientes confiáveis e previsíveis (MORGAN, 2007).

Estrutura organizacional pode ser entendida como a forma e a relação que orienta e organiza o potencial humano dentro da organização, independentemente de seu tamanho, atividade e objetivo. Sobre a matéria, Mintzberg (2009: 12) complementou:

A estrutura de uma organização pode ser definida simplesmente como a soma total das maneiras pelas quais o trabalho é dividido em tarefas distintas e, depois, como a coordenação é realizada entre essas tarefas.

A gestão do negócio ou a coordenação das atividades deve refletir e orientar o pensamento ou a visão do negócio captada de seu principal acionista, não dando espaço a visões paralelas que possam afetar o objetivo pretendido. De acordo com Certo \& Peter (1993), que descreveram a existência de dois tipos básicos de estrutura organizacional: a estrutura formal descrita no organograma da organização e a

1 Produto interno bruto. estrutura informal desenvolvida pelo relacionamento social dos membros da organização. Morgan (2007: 196-197) complementou a ideia, afirmando que:

Muito frequentemente, a estrutura organizacional, regras e regulamentações e procedimentos são vistos como instrumentos racionais que pretendem ajudar o desempenho de um trabalho. Uma visão política desses arranjos, no entanto, sugere que em muitas situações eles são mais bem compreendidos como produtos e reflexos de uma luta pelo controle político.

Certo \& Peter (1993) identificaram cinco tipos de estruturas organizacionais normalmente encontradas: a simples; a funcional; a divisional; a de unidades estratégicas de negócios; e a estrutura-matriz. Os referidos autores ainda asseveraram que, dependendo da experiência do gestor, as pequenas empresas podem concorrer efetivamente com grandes indústrias, devido à sua rapidez e flexibilidade em implementar estratégias. Mintzberg (2009) afirmou que, em decorrência da centralização do poder, a tomada de decisão é mais flexível e o ambiente da estrutura simples tende a ser, ao mesmo tempo, simples e dinâmico.

Mintzberg (2009) também identificou cinco configurações de estrutura para descrever todas as organizações: estrutura simples; burocrática mecanizada; burocrática profissional; forma divisionalizada; e adhocracia.

A administração não fornece uma definição clara sobre a palavra flexibilidade, de sorte que outras áreas do conhecimento podem auxiliar defini-la, a exemplo da área desportiva, que utiliza a palavra "flexibilidade" para designar características dos atletas. Entretanto, Sennett (2009: 53) forneceu um significado ao vocábulo em destaque:

A palavra "flexibilidade" entrou na língua inglesa no século quinze. Seu sentido derivou originalmente da simples observação de que, embora a árvore se dobrasse ao vento, seus galhos sempre voltavam à posição normal. "Flexibilidade" designa essa capacidade de ceder e recuperar-se da árvore, o teste e restauração de sua forma. Em termos ideais, o comportamento humano flexível deve ter a mesma força tênsil: ser adaptável a circunstâncias variáveis, mas não quebrado por elas. 
A sociedade hoje busca meios de destruir os males da rotina com a criação de instituições mais flexíveis. As práticas de flexibilidade, porém, concentram-se mais nas forças que dobram as pessoas.

Slack, Chambers \& Johnston (2009: 267-268) relataram que as novas tecnologias, mudanças mercadológicas e sociais incorporam mudanças na administração da produção, incluindo três aspectos: o primeiro deles é a flexibilidade de habilidades, que orienta a força de trabalho adaptável em diversas tarefas; o segundo é a flexibilidade do tempo, que norteia a necessidade das pessoas e das empresas de alinharem a disponibilidade de tempo com o aumento de demanda, ou seja, "conjugar a oferta de trabalhadores com a demanda por seus trabalhos é o objetivo de 'horário flexível' ou flexi-tempo". E, finalmente, a flexibilidade de localização, o teletrabalho, que orienta o exercício de algumas funções indiretas que possam ser desempenhadas fora da área produtiva, desde que exista um canal de comunicação, ou seja, "com a percepção deste fato, surgiu a ideia do teletrabalho, também conhecido como 'locais de trabalhos alternativos', 'trabalho flexível', trabalho em casa e escritório virtual".

Hardjono (1995 apud VAN MARREWIJK, 2010) apresentou um modelo (FourPhase ${ }^{\circledR}$ ) como ferramenta de análise organizacional, que possibilita a escolha da estratégia adequada para a implementação de meIhorias na organização por meio de um desempenho sustentável e do desenvolvimento de competências.

Van Marrewijk (2010) relatou que o modelo sugere que as organizações optem por questões internas ou externas e, ao mesmo tempo, pelo controle ou pela mudança. Ambos os pares são dicotomias, embora cada um dos lados dessas dicotomias seja importante; em um cenário específico, apenas um dos lados possui a restrição (interno ou externo) ou a solução (controle ou mudança). A Figura 1 insere nos quatro elementos os valores fundamentais da organização, a representação das dicotomias básicas, que resultam em quatro orientações estratégicas.

Entre alguns focos importantes, van Marrewijk (2010: 89) revelou que o "cliente é sensível a qualidade dos serviços, o que exige uma abordagem flexível da organização (flexibilidade)". Porém, a implantação da flexibilidade deve ser avaliada e



Figura 1: Os recursos do núcleo, as dicotomias, e orientações estratégicas

Fonte: Hardjono (1995 apud van MarRewij, 2010: 87) adaptado.

planejada, pois sua aplicação inadequada pode levar a empresa a obter prejuízos tanto no processo produtivo como na gestão de pessoas. Pereira, Forno \& Tubino (2008) afirmaram que empresas realizam altos investimentos sem identificar onde exatamente necessitam da flexibilidade, indicando a necessidade de desdobrar a flexibilidade para especialização, processos, operação ou gerenciamento com a finalidade de arquitetar uma fábrica inteligente.

A evolução tecnológica e mercadológica representada pela diferenciação nas necessidades dos compradores e a abertura dos mercados abrigou as organizações a adotarem a flexibilização organizacional a fim de obter sustentação nos negócios. O foco desta flexibilização é a capacidade de inovação das pessoas. "A partir dos anos 1980, as empresas brasileiras (...), procuraram incorporar um novo modelo de gestão que agilizasse o processo de produção através das tecnologias da informação e que promovesse de maneira mais consciente e envolvimento do empregado no processo de trabalho" (TENÓRIO 2002: 15).

Ansoff \& McDonnell (1993: 178-179) argumentaram que "O objetivo de flexibilidade é uma característica de empresas empreendedoras. A flexibilidade interna é conseguida graças à configuração de recursos, capacidades, habilidades e potencialidades da empresa". 
Tachizawa \& Scaico (2006: 78) revelaram, por sua vez, uma alternativa de modelo de organização flexível, segregando as atividades produtivas das atividades de apoio e sugerindo que as atividades que não fizerem parte da estratégia organizacional sejam alocadas em fornecedores externos.

Mendes (2002: 29) declarou ainda que "o tema flexibilidade organizacional está relacionado a estratégias gerenciais que influenciam a efetividade e competitividade das empresas, e o mesmo pode ser analisado tanto sob perspectivas mais abrangentes como sob perspectivas mais específicas". Tenório (2002) distinguiu organizações flexíveis de não flexíveis, fazendo um paralelo entre o período fordista e do pósfordista, conforme evidencia o Quadro 1, a seguir.

Mendes (2002) desenvolveu em sua pesquisa um instrumento que identificou três fatores distintos da flexibilidade organizacional, que levam à definição de um único fator, o qual denominou de "modelo organizacional flexível".
Considerando-se o modelo apresentado, no estudo da flexibilidade organizacional nas pequenas industriais metalúrgicas de Osasco e região, será utilizada a definição apresentada por Mendes (2002: 83):

Modelo organizacional flexível: que indica se a forma de organização do trabalho e o funcionamento do processo decisório praticado pela empresa estão focados nos clientes e se favorecem o uso racional de recursos; a interação dos processos de trabalho; a autonomia das equipes e a descentralização das decisões.

Os fatores que compõe o modelo organizacional flexível e suas definições estão apresentados no Quadro 2.

As pequenas indústrias estão inseridas em um importante setor da economia brasileira - as micro e pequenas empresas (MPEs). O Sebrae (2005) revelou que as MPEs respondem por 99,2\% do número total de empresas formais no Brasil, por $57,2 \%$ do total de empregos e por $26 \%$ da massa salarial. "Um dos

Quadro 1: Caracterização do período fordista x pós-fordista

\begin{tabular}{|l|l|}
\hline Fordismo & Pós-fordismo \\
\hline Rigidez organizacional & Flexibilização organizacional \\
\hline $\begin{array}{l}\text { Técnica repetitiva de produção de serviços } \\
\text { ou produtos padronizados }\end{array}$ & $\begin{array}{l}\text { Diferenciação integrada da organização da produção e do trabalho sob a trajetória } \\
\text { de inovações tecnológicas em direção à democratização das relações sociais nos } \\
\text { sistemas-empresa }\end{array}$ \\
\hline Sistemas mecânicos & Sistemas orgânicos \\
\hline
\end{tabular}

Fonte: adaptado de Tenório (2002).

Quadro 2: Fatores do modelo flexível de gestão

\begin{tabular}{|l|l|}
\hline Fatores & Descrição \\
\hline Organização do trabalho - OT & $\begin{array}{l}\text { Propõe analisar se a maneira como foram organizadas e planejadas as atividades } \\
\text { privilegia os objetivos organizacionais em detrimento dos setoriais ou individuais; } \\
\text { se facilita processos de mudança; se busca a utilização racional de recursos, a } \\
\text { melhoria contínua dos processos de trabalho, a integração das equipes e a visão } \\
\text { global das atividades. }\end{array}$ \\
\hline $\begin{array}{l}\text { Gestão de pessoas e processo } \\
\text { decisório - GP }\end{array}$ & $\begin{array}{l}\text { Visa a verificar como funciona a relação líder-liderado no processo decisório e se, } \\
\text { no processo de delegação de autoridade e responsabilidade, há um estímulo à } \\
\text { participação e ao comprometimento. São enfocados aspectos como descentralização } \\
\text { e autonomia; processo de comunicação; e participação dos empregados na tomada } \\
\text { de decisão. }\end{array}$ \\
\hline Foco no cliente - FC & $\begin{array}{l}\text { Tem por objetivo verificar se a gestão da organização está centrada nos clientes. } \\
\text { Para isso, propõe-se a analisar se os requisitos de qualidade, as necessidades e o nível } \\
\text { de satisfação dos clientes são considerados no planejamento e na execução das } \\
\text { atividades, bem como se a unidade conhece seus clientes. }\end{array}$ \\
\hline
\end{tabular}

Fonte: Mendes (2002: 58-59). 
papéis designados a elas é a oferta de produtos e serviços demandados pela sociedade que só podem ser rentáveis se comercializados em pequena escala" (SANTOS, FerReIRA \& Faria, 2009). Esta instituição, apesar de constituir um dos pilares da economia brasileira, segundo o Sebrae (2005), apresenta um aspecto alarmante: aproximadamente $60 \%$ das MPEs morrem em até o quatro anos de sua existência.

A Lei Geral da Micro e Pequena Empresa, promulgada em 14 de dezembro de 2006, define microempresa aquela que auferir receita bruta igual ou inferior a 240 mil reais e empresa de pequeno porte aquela que auferir receita bruta anual igual ou inferior a $\mathrm{R} \$$ 2,4 milhões.

O Sebrae utiliza o conceito número de trabalhadores para a classificação das MPEs, conforme demonstrado no Quadro 3.

Quadro 3: Classificação por número de funcionários

\begin{tabular}{|l|c|c|}
\hline Ramo de atividade & Microempresa & Pequena empresa \\
\hline Indústria e construção & $\begin{array}{c}\text { Até 19 } \\
\text { funcionários }\end{array}$ & $\begin{array}{c}\text { De } 20 \text { a } 99 \\
\text { funcionários }\end{array}$ \\
\hline Comércio e serviços & $\begin{array}{c}\text { Até 09 } \\
\text { funcionários }\end{array}$ & $\begin{array}{c}\text { De } 10 \text { a } 49 \\
\text { funcionários }\end{array}$ \\
\hline
\end{tabular}

Fonte: Sebrae-SP.

As MPEs encontram diversas dificuldades em desenvolver estratégias por não possuírem recursos financeiros, investimentos em setores críticos que possam proporcionar maior competitividade. A esse respeito, Vieira (2002) destacou que "(...) estas tem várias origens, dentre as quais, a falta de recursos humanos capacitados, a falta de métodos estruturados e a complexidade das relações da empresa com o meio onde ela está inserida". Já Hasenclever et al. (2006) incluíram outras dificuldades das pequenas empresas, relacionadas à distribuição de seus produtos:

Um dos maiores desafios das pequenas e médias empresas brasileiras é a distribuição de seu produto no mercado internacional, conforme constatado na primeira seção, levando a uma participação relativa nesse mercado em torno de $5 \%$. Mesmo no mercado nacional, essas empresas em geral não dominam os canais de distribuição e são dependentes desses canais, não possuem marca própria ou marketing dirigido a seu produto, ficando à mercê dos intermediários que acabam por consumir grande parte das margens de sua comercialização. Nesse sentido, o mercado internacional poderia ser uma importante fonte de diversificação, reduzindo o risco das crises locais e diversificando os canais de distribuição.

Apesar de as MPEs encontrarem grandes dificuldades em sua gestão, verificam-se nelas algumas características, como dinamismo, flexibilidade, inovação e simplicidade, que podem proporcionar fatores de sucesso para sua sobrevivência. Silva (2004) considerou, em seu trabalho, que as empresas de pequeno porte têm demonstrado flexibilidade para constituir arranjos organizacionais, valorizando a configuração simples, mais dinâmica, inovadora e sensível às exigências de mercado, e prestando atendimento personalizado ao consumidor. Também caracterizam essas empresas a criação de empregos, a disposição das oportunidades ao empreendedorismo, a capacidade de diversificação de produtos e processos, proporcionando maior competitividade e facilitando a cooperação.

A necessidade de sobrevivência e longevidade direciona as empresas a adotarem estratégias criativas e inovadoras. Wright (2009) identificou, em sua pesquisa, que fatores como flexibilidade organizacional e integração da comunidade foram responsáveis pela sobrevivência de organizações rurais há mais de 30 anos nos Estados Unidos. Levy (1992) complementou a informação, asseverando que a flexibilidade na organização é a saída para minimizar o efeito das turbulências do meio externo e reduzir a necessidade de inúteis simulações de cenários futuros. Phillips \& Wright (2009) comentaram que as organizações estão descobrindo que a sua capacidade de responder às imprevisíveis mudanças do mercado está se tornando um fator-chave na sua própria sobrevivência. Os processos da capacidade de adaptação e de negócios para as preferências do cliente (flexibilidade) se tornaram uma necessidade para sistemas on-line.

As MPEs, por possuírem estrutura simples e dinâmica, estão dispostas a oferecer produtos e serviços com menores custos. Levy (1992) definiu flexibilidade como a liberdade de ação na aplicação de recursos, a forma de aumentar a velocidade na aplicação e combinação de recursos e inovação. 


\section{ANÁLISE E RESULTADOS DA PESQUISA}

O questionário respondido pelo gestor continha duas partes, a primeira delas caracterizando o gestor e a empresa. A amostra respondente está representada por 20 empresas, onde se verificaram os seguintes dados: (a) quanto ao número de trabalhadores, eles estão distribuídos na seguinte proporção: 15\% na faixa de 80 a 99 trabalhadores; $15 \%$ na faixa de 60 a 79 trabalhadores; $25 \%$ na faixa de 40 a 59 trabalhadores; $45 \%$ na faixa de 20 a 39 trabalhadores; (b) quanto à longevidade, $85 \%$ das empresas apresentam-se com mais de dez anos de existência; (c) quanto ao faturamento anual, 83,3\% das organizações pesquisadas têm um rendimento superior a $R \$ 2,4$ milhões por ano. Vale dizer que duas empresas deixaram de responder a esta questão. $\mathrm{O}$ faturamento indicado demonstra que estas empresas não se enquadram na Lei Geral das Micro e Pequenas Empresas por excederem o limite anual; (c) quanto às características pessoais dos gestores, $90 \%$ dos entrevistados responderam pertencer ao sexo masculino e $10 \%$, ao sexo feminino. O nível de escolaridade do principal gestor também pode indicar fator de sucesso para uma pequena indústria metalúrgica da região Osasco, em São Paulo - a pesquisa indicou que $75 \%$ dos gestores possuem curso superior ou pós-graduação.

A segunda parte do questionário enviado às pequenas indústrias metalúrgicas indicava 20 questões, sendo oito sobre a organização no trabalho, seis sobre gestão de pessoas e processo decisório e seis sobre foco no cliente, com escala de concordância do tipo Likert de 6 pontos, onde 1 representa a total discordância e 6 , a total concordância sobre a afirmação indicada.

A seguir, serão analisadas as respostas às afirmativas relativas aos três fatores pesquisados. Foram consideradas, para o nível de discordância, as escalas 1 e 2 ("discordo totalmente" e "discordo", respectivamente); para o nível de neutralidade, as escalas 3 e 4 ("discordo parcialmente" e "concordo parcialmente"); e, para o nível de concordância, as escalas 5 e 6 ("concordo" e "concordo totalmente").

\subsection{Fator "foco no cliente"}

O fator "foco no cliente" obteve concordância em todas afirmativas. O Quadro 4 revela a quantidade de respostas por questão além de apresentar a mediana das respostas na escala de concordância.

O resultado apresentado pelo Gráfico 1, a seguir, resume as respostas fornecidas pelos gestores às seis perguntas relacionadas ao fator "foco no cliente", representadas pelo resultado percentual relativo à escala Likert de 6 pontos. A maior concentração está na concordância a respeito do referido fator, representado por $79 \%$ nas respostas dos gestores.

Quadro 4: Mediana por questão - fator "foco no cliente"

\begin{tabular}{|c|c|c|c|c|}
\hline Fator & & Questões & $\begin{array}{l}\text { Quantidade } \\
\text { de } \\
\text { respostas }\end{array}$ & $\begin{array}{l}\text { Mediana do grau } \\
\text { de concordância } \\
\text { na escala likert }\end{array}$ \\
\hline \multirow{6}{*}{ 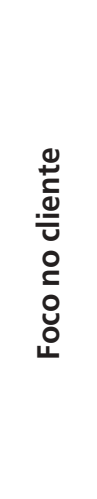 } & 7 & $\begin{array}{l}\text { A qualidade dos produtos e serviços é uma prioridade das equipes } \\
\text { (ou pessoas) na empresa (FC1). }\end{array}$ & 20 & 6 \\
\hline & 8 & $\begin{array}{l}\text { A empresa mantém o cliente informado sobre seu trabalho, seus produtos e } \\
\text { serviços ( } F C 2 \text { ). }\end{array}$ & 20 & 5 \\
\hline & 9 & $\begin{array}{l}\text { A empresa preocupa-se em criar, junto aos clientes, uma imagem positiva e } \\
\text { de qualidade dos seus produtos e serviços ( } F C 3 \text {. }\end{array}$ & 20 & 5,5 \\
\hline & 10 & Os clientes conhecem os produtos e serviços da empresa (FC4). & 20 & 5 \\
\hline & 11 & $\begin{array}{l}\text { As sugestões dos clientes são consideradas no momento de estabelecer os } \\
\text { requisitos de qualidade dos produtos e serviços oferecidos pela empresa (FC5). }\end{array}$ & 19 & 5 \\
\hline & 12 & $\begin{array}{l}\text { A prioridade na execução das atividades e dos processos de trabalho da empresa } \\
\text { é definida em função das necessidades e demandas dos clientes (FC6). }\end{array}$ & 20 & 5 \\
\hline
\end{tabular}

Fonte: dados da pesquisa. 
Gráfico 1: Resumo das questões sobre o fator "foco no cliente"

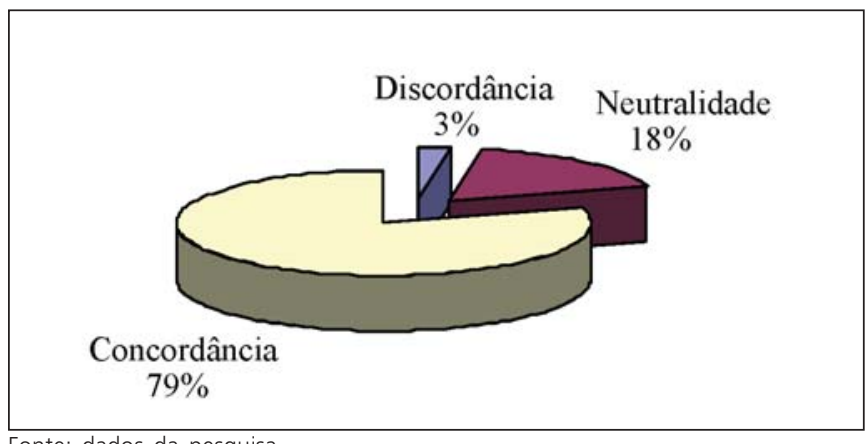

Fonte: dados da pesquisa.

\subsection{Fator "gestão de pessoas e processo decisório"}

O fator "gestão de pessoas e processo decisório" apresentou neutralidade quando os gestores foram perguntados se os atos administrativos são passados aos empregados e se estes participam do processo decisório. O Quadro 5, abaixo, revela a quantidade de respostas por questão, além de apresentar a mediana das respostas na escala de concordância.

O resultado apresentado pelo Gráfico 2 resume as respostas das seis perguntas submetidas aos gestores, alcançando o grau de concordância de $53 \%$ para o fator pesquisado, embora tenha sido encontrado um grau de neutralidade e discordância de $67 \%$ na questão 15 ("A chefia da empresa propicia
Gráfico 2: Resumo das questões sobre o fator gestão de pessoas e processo decisório

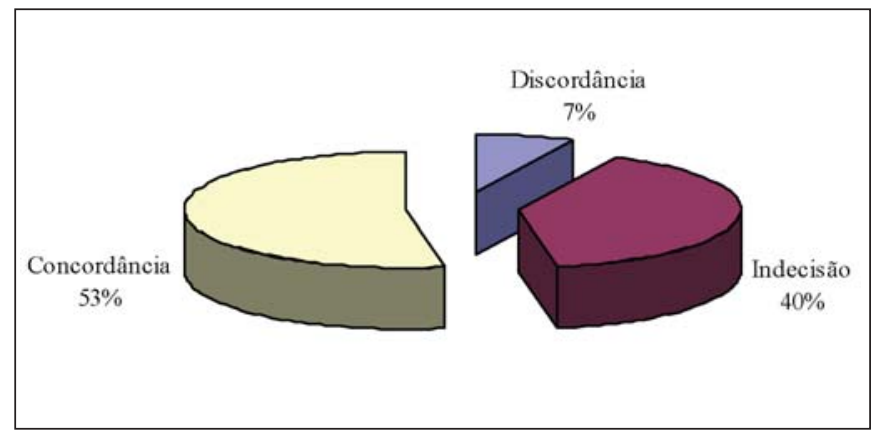

Fonte: dados da pesquisa.

a participação de todos os níveis hierárquicos"). Percebeu-se, na realização da entrevista, segurança nas respostas do gestor, principalmente na questão relativa à não participação das pessoas no processo decisório, demonstrando a falta de valorização deste requisito de flexibilidade na visão do gestor.

\subsection{Fator "organização do trabalho"}

Os gestores demonstraram neutralidade quando perguntados se os processos de trabalhos são executados de maneira eficiente. O Quadro 6 revela a quantidade de respostas por questão, além de apresentar a mediana das respostas na escala de concordância.

Quadro 5: Mediana por questão - fator "gestão de pessoas e processo decisório"

\begin{tabular}{|c|c|c|c|c|}
\hline Fator & \multicolumn{2}{|r|}{ Questões } & $\begin{array}{l}\text { Quantidade } \\
\text { de } \\
\text { respostas }\end{array}$ & $\begin{array}{c}\text { Mediana do grau } \\
\text { de concordância } \\
\text { na escala likert }\end{array}$ \\
\hline \multirow{6}{*}{  } & 13 & $\begin{array}{l}\text { Os empregados são informados sobre os atos administrativos (decisões, } \\
\text { compromissos, procedimentos) da empresa (GP1). }\end{array}$ & 20 & 4,5 \\
\hline & 14 & $\begin{array}{l}\text { As decisões relativas à sua empresa são tomadas em conjunto pela chefia e } \\
\text { pela equipe (ou pessoas) responsável pelo trabalho (GP2). }\end{array}$ & 20 & 5 \\
\hline & 15 & $\begin{array}{l}\text { A chefia da empresa propicia a participação de todos os níveis hierárquicos no } \\
\text { processo decisório (GP3). }\end{array}$ & 18 & 4 \\
\hline & 16 & $\begin{array}{l}\text { A chefia de sua empresa concede autonomia às equipes (ou pessoas) para que } \\
\text { estas decidam sobre como executar seu trabalho (GP4). }\end{array}$ & 18 & 4,5 \\
\hline & 17 & $\begin{array}{l}\text { É uma atitude comum das chefias dar aos empregados feedback quando ao seu } \\
\text { desempenho (GP5). }\end{array}$ & 18 & 5 \\
\hline & 18 & $\begin{array}{l}\text { As informações necessárias à realização do trabalho são repassadas às equipes } \\
\text { (ou pessoas) no momento adequado (GP6). }\end{array}$ & 18 & 5 \\
\hline
\end{tabular}

Fonte: dados da pesquisa. 
Quadro 6: Mediana por questão - fator "organização do trabalho"

\begin{tabular}{|c|c|c|c|c|}
\hline Fator & \multicolumn{2}{|r|}{ Questões } & $\begin{array}{l}\text { Quantidade } \\
\text { de } \\
\text { respostas }\end{array}$ & $\begin{array}{l}\text { Mediana do grau } \\
\text { de concordância } \\
\text { na escala likert }\end{array}$ \\
\hline \multirow{8}{*}{ 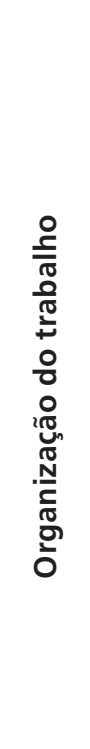 } & 19 & $\begin{array}{l}\text { As diferentes equipes (ou pessoas) de trabalho da empresa atuam em } \\
\text { parceria para atingir objetivos comuns (OT1). }\end{array}$ & 18 & 5 \\
\hline & 20 & $\begin{array}{l}\text { As equipes (ou pessoas) de sua empresa adotam novos métodos de trabalho, } \\
\text { visando a aumentar o nível de eficiência da empresa (OT2). }\end{array}$ & 18 & 5 \\
\hline & 21 & $\begin{array}{l}\text { Nos seus processos de trabalho, as equipes (ou pessoas) utilizam a melhor } \\
\text { forma de executar as atividades (menos custos e melhores resultados) (OT3). }\end{array}$ & 18 & 4 \\
\hline & 22 & $\begin{array}{l}\text { Os empregados conhecem quais são os processos e atividades principais para } \\
\text { empresa atingir sua missão (OT4). }\end{array}$ & 18 & 5 \\
\hline & 23 & $\begin{array}{l}\text { Os principais processos de trabalho de empresa estão descritos } \\
\text { formalmente (OT5). }\end{array}$ & 20 & 5 \\
\hline & 24 & $\begin{array}{l}\text { A distribuição dos diferentes recursos (humanos, financeiros, materiais) atende } \\
\text { a uma prioridade que privilegia os processos e as atividades da empresa (OT6). }\end{array}$ & 20 & 5 \\
\hline & 25 & $\begin{array}{l}\text { Os processos de trabalho da empresa são analisados periodicamente, visando } \\
\text { a verificar a possibilidade de melhoria (OT7). }\end{array}$ & 20 & 5 \\
\hline & 26 & $\begin{array}{l}\text { As equipes (ou pessoas), sempre que necessário, têm facilidade em adequar } \\
\text { suas atividades e seus processos de trabalho para atender às demandas e aos } \\
\text { objetivos organizacionais (OT8). }\end{array}$ & 20 & 4,5 \\
\hline
\end{tabular}

Fonte: dados da pesquisa.

O resultado apresentado pelo Gráfico 3 resume as respostas às oito perguntas submetidas aos gestores, alcançando o grau de concordância de $61 \%$ para o fator pesquisado. Particularmente as questões 21 e 26 remeteram o grau de concordância para a neutralidade ou discordância, indicando assim uma oportunidade de melhoria na flexibilidade, na forma como as pessoas executam suas tarefas, objetivando menores custos e melhores resultados, e nas questões relativas à facilidade em adequar suas atividades e seus processos de trabalho para atender às demandas e aos objetivos organizacionais.

Gráfico 3: Resumo das questões sobre o fator organização do trabalho

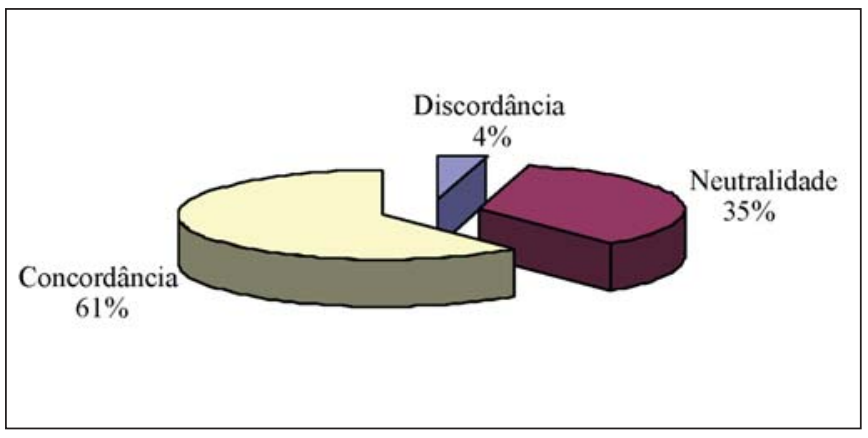

Fonte: dados da pesquisa.

\subsection{Modelo organizacional flexível}

Avaliando-se o modelo organizacional flexível proposto por Mendes (2002), composto pelos três fatores pesquisados - foco no cliente, gestão de pessoas e processo decisório e organização do trabalho -, verifica-se concordância com o modelo organizacional flexível para a maioria das características estudadas. O Gráfico 4, abaixo, demonstra como resultado o grau de $65 \%$ de concordância em relação ao modelo estudado.

Gráfico 4: Resumo da avaliação do modelo organizacional flexível

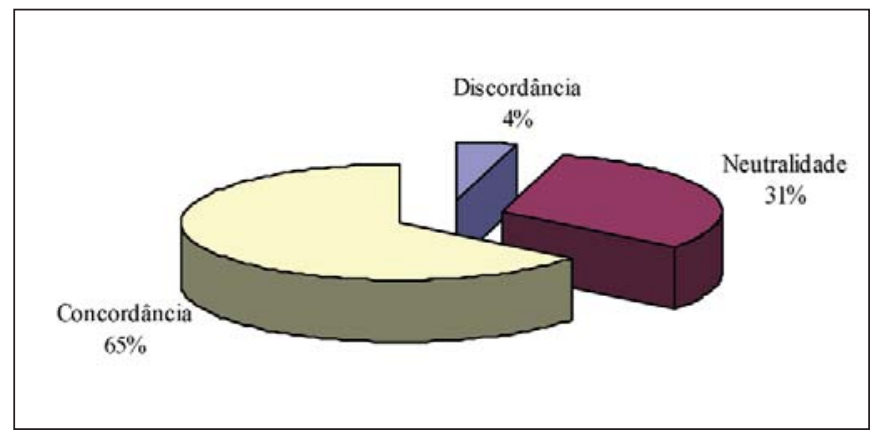

Fonte: dados da pesquisa. 
A percepção do gestor revela que as pessoas não são envolvidas no processo decisório; também evidencia que as pessoas não executam o trabalho da melhor forma (menor custo, melhor resultado), não estando engajadas nos objetivos organizacionais. Esse fato pode ser reflexo de traços históricos culturais da sociedade, que divide o gestor e o trabalhador em duas classes sociais distintas, ou simplesmente os objetivos organizacionais não estão alinhados aos objetivos pessoais dos trabalhadores. Braverman (1987: 319) indicou que a força de trabalho é a parte animada do capital, e complementou a ideia: "Trabalho e capital são polos opostos da sociedade capitalista. Esta polaridade começa em cada empresa e é concretizada em escala nacional e internacional como uma gigantesca dualidade de classes que domina a estrutura social". Sobre tal aspecto, Morgan (2007: 185) manifestou-se:

Os empregados trazem para o local de trabalho aspirações e visões sobre o que o futuro thes reserva, que constituem a base para os interesses de carreira, que podem ser independentes da tarefa que está sendo realizada. Os empregados também trazem interesses pessoais, suas personalidades, atitudes pessoais, valores, preferências, crenças, compromissos fora do trabalho que determinam a maneira como agem em relação e à carreira.

\subsection{Análise quantitativa com Alpha de Cronbach}

A análise por meio do Alpha de Cronbach objetiva mostrar a consistência das diversas variáveis para a flexibilidade organizacional. O cálculo do valor de á de Cronbach foi feito utilizando-se o software SPSS v17. O Quadro 7 apresenta o resultado para índice Alpha de Cronbach.

Quadro 7: Índice $\alpha$ de Cronbach - Reliability statistics

\begin{tabular}{|c|c|c|}
\hline $\begin{array}{c}\text { Cronbach's } \\
\text { Alpha }\end{array}$ & $\begin{array}{c}\text { Cronbach's Alpha } \\
\text { based on } \\
\text { standardized items }\end{array}$ & N of items \\
\hline, 936 &, 935 & 20 \\
\hline
\end{tabular}

Fonte: dados da pesquisa com a aplicação do software SPSS v17.
Guimarães, Brandon \& Guimarães (2010) aceitaram como confiável, em seu estudo, o coeficiente de Alpha de Cronbach maior que 0,50, embora tenham interpretado que o índice maior que 0,70 é indicado para estudos mais rigorosos. Khoury \& Analoui (2010) confirmaram 0,70 como um bom índice de confiabilidade do coeficiente de Alpha de Cronbach.

O valor obtido do a de Cronbach, neste caso, foi de 0,936. Este indicador assume valores entre 0 e 1 e trabalha com a premissa de que as correlações entre os itens são positivas. De forma geral, considera-se que um bom valor do á seria 0,70 ou superior (obtido com uma amostra significativa). Esta regra deve ser aplicada com prudência, uma vez que o grau adequado de fidedignidade depende da utilização do instrumento. Pereira (2001: 87) afirmou que, "para interpretar o á de Cronbach, pode-se entendê-lo como um coeficiente de correlação ao quadrado $\left(R^{2}\right) \mathrm{com}$ uma suposta medida real do fenômeno estudado".

Avaliando-se a Scale mean if item deleted (escala média se o item é desprezado), verificou-se a média de 93,82 com um desvio padrão de 13,087, conforme mostra o Quadro 8.

Quadro 8: Estatística da escala - Scale statistics

\begin{tabular}{|l|c|c|c|}
\hline Mean & Variance & Std. deviation & N of items \\
\hline 93,82 & 171,279 & 13,087 & 20 \\
\hline
\end{tabular}

Fonte: dados da pesquisa com a aplicação do software SPSS v17.

Mais importante do que analisar o coeficiente é estar atento para as informações sobre o comportamento de cada item compondo o indicador (PEREIRA, 2001). Quanto mais um item diminui a média, mais importante é ele de acordo com Pereira (2001). Aplicando-se o software SPSS v17, observa-se que basicamente todos os itens possuem importância semeIhante, isto é, caso um deles fosse desconsiderado, a média cairia para um valor em torno de 89,00.

Cronbach's Alpha IF Item Deleted (á de Cronbach se o item é desprezado): mostra o impacto que teria a retirada do fator para elevar o á de Cronbach. 0 valor do á com os 20 itens é de 0,936. Pode-se considerar que todos os fatores estão adequadamente correlacionados. 
Corrected item-total correlation (Correlação corrigida entre item e total): mostra o coeficiente de correlação de Pearson (r) entre o item (proposição) e o indicador total depurado de sua própria contribuição. O primeiro tipo de impacto é o que tem menor correlação com o indicador total. Santos et al. (2010) e Pereira \& Amaral (2004) consideraram a correlação item-total satisfatória por ser maior que 0,40. No presente estudo, os itens GP4 $(0,215)$, FC4 $(0,311)$ e GP3 $(0,329)$ se afastam do valor 0.4 . Em suma: estes três itens não estão adequadamente correlacionados com a flexibilidade organizacional (Quadro 9).

Scale variance if item deleted (variância da escala, se o item é desprezado): neste caso, interessaria eliminar os itens que promovem uma redução maior na variância. A variância atual da escala é de 171,279 (como mostra o Quadro 8). A remoção do item GP5 ("É uma atitude comum das chefias dar aos empregados feedback quando ao seu desempenho") reduziria a variância para 144,5. Significa que este é o fator que apresentou maior variabilidade.

\section{CONSIDERAÇÕES FINAIS}

A flexibilidade utilizada em sua forma primária, ou entendida como estrutura organizacional ou, ainda, como modelo de gestão, sempre estará contribuindo com a adaptabilidade da estrutura ou espécie a fim de garantir sua perenidade.

A importância da aplicação da flexibilidade organizacional está em manter a empresa preparada para atender às demandas do mercado no instante em que elas surgem, e em desenvolver uma filosofia de organização flexível e acreditar que esta atitude pode fornecer competitividade para as MPEs, quebrando assim a estatística de alta mortalidade encontrada neste segmento empresarial tão importante para a geração de empregos e renda na sociedade.

Com isso, a flexibilidade organizacional torna-se uma importante característica que auxilia o aumento de competitividade por gerar agilidade nas respostas e adaptação aos processos, ajudando a promover a sobrevivência e o crescimento das empresas por gerar uma importante vantagem competitiva.

As MPEs enfrentam muitas dificuldades em se manter no mercado por um longo período. Com isso, buscam-se modelos com a finalidade de aprimorar a gestão deste importante segmento gerador de empregos e celeiro de inovação e criatividade.

A pesquisa revelou, por meio das respostas dos gestores das pequenas indústrias metalúrgicas da região de Osasco, em São Paulo, sua concordância com o modelo organizacional flexível, compreendendo inclusive todos os seus fatores, como "foco no cliente", "gestão de pessoas e processo decisório" e "organização do trabalho".

Quando avaliado particularmente o fator "gestão de pessoas e processo decisório", observa-se ainda um campo carente em flexibilidade, talvez gerado pelo fato de as MPEs possuírem estrutura organizacional simples, em que o gestor muitas vezes centraliza a tomada de decisão. Tal constatação indica, assim, um espaço para a empresa se tornar mais flexível, de maneira que o gestor poderá desenvolver melhor os seus liderados com a aplicação de feedback, a fim de permitir sua participação na tomada de decisão e no complemento das ideias para a evolução do negócio.

O fator "foco no cliente" foi o que apresentou com maior aderência à flexibilidade, embora ainda exista um ponto para melhoria desse aspecto, que é

Quadro 9: Questões que não estão adequadamente correlacionadas com o modelo organizacional flexível

\begin{tabular}{|c|l|c|}
\hline & $\begin{array}{l}\text { Questões que não estão adequadamente correlacionadas } \\
\text { com o modelo organizacional flexível }\end{array}$ & $\begin{array}{c}\text { Corrected } \\
\text { item-total } \\
\text { correlation }\end{array}$ \\
\hline 16 & $\begin{array}{l}\text { A chefia de sua empresa concede autonomia às equipes (ou pessoas) para que estas decidam sobre } \\
\text { como executar seu trabalho (GP4). }\end{array}$ & 0,215 \\
\hline 10 & Os clientes conhecem os produtos e serviços da empresa (FC4). & 0,311 \\
\hline 15 & A chefia da empresa propicia a participação de todos os níveis hierárquicos no processo decisório (GP3). & 0,329 \\
\hline
\end{tabular}

Fonte: dados da pesquisa com a aplicação do software SPSS v17. 
a aproximação do cliente com os produtos da empresa.

A pesquisa revelou também, a partir da amostra pesquisada, que as empresas participantes, em sua maioria, possuem mais de dez anos de existência e apresentam um faturamento superior a $\mathrm{R} \$ 2,4$ milhões por ano, além de revelar que a maioria de seus gestores possui nível de escolaridade superior ou pósgraduação. Estas fortes características encontradas na amostra podem ser interpretadas como um perfil de sucesso, já que indicam longevidade e competitividade nas empresas pesquisadas. Sendo assim, pode-se inferir que a flexibilidade organizacional contribui com a longevidade e o sucesso das empresas que adotam este modelo, aliado ao bom nível educacional de seus gestores.

\section{LIMITAÇÕES DA PESQUISA E RECOMENDAÇÕES}

Quanto às limitações desta pesquisa, entende-se que os resultados não podem ser generalizados para o setor das pequenas indústrias metalúrgicas da região de Osasco, no Estado de São Paulo, tampouco para as MPEs, por se tratar de um estudo que está representado apenas por uma pequena parte das empresas, além de conter somente os dados obtidos dos gestores.

Recomenda-se para aprofundamento e conclusões mais precisas, bem como uma observação mais profunda nos aspectos levantados, um novo estudo incluindo o ponto de vista de outros profissionais da organização. Também se recomenda a aplicação deste instrumento em outras regiões e em diferentes organizações, de modo a poder gerar um parâmetro de maior compreensão de organização flexível.

\section{REFERÊNCIAS}

Ansoff, H. Igor \& McDonnelL, Edward J. Implantando a administração estratégica. 2. ed. São Paulo: Atlas, 1993.

Brasil. Lei Complementarn. 123, de 14 de dezembro de 2006. Institui o Estatuto Nacional da Microempresa e da Empresa de Pequeno Porte; altera dispositivos das Leis n. 8.212 e n. 8.213, ambas de 24 de julho de 1991, da Consolidação das Leis do Trabalho - CLT, aprovada pelo DecretoLei n. 5.452, de $1^{\circ}$ de maio de 1943, da Lei n. 10.189, de 14 de fevereiro de 2001, da Lei Complementar n. 63, de 11 de janeiro de 1990; e revoga as Leis $n$. 9.317, de 5 de dezembro de 1996, e n. 9.841, de 5 de outubro de 1999. Brasília: DOU, 2006.

Braverman, Harry. Trabalho e capital monopolista: a degradação do trabalho no século XX. 3. ed. Rio de Janeiro: Guanabara, 1987.

Certo, Samuel C. \& Peter, J. Paul. Administração estratégica: planejamento e implantação da estratégia. São Paulo: Makron Books, 1993.

Guimarães, Tor, Brandon, Bransford \& Guimarães, Erik Ryan. Empirically testing some major factors for bank innovation success. Journal of Performance Management, v. 23, n. 2, p. 34, September, 2010. Disponível em: <http://search.proquest.com/ docview/856125539? accountid=34749>. Acesso em: 16 de maio de 2011.

Hasenclever, Lia; Aguiar, Virgínia Motta; Zissimos, Isleide \& CÂNDIDO, Gesinaldo Ataíde. Desafios à exportação industrial de pequenas e médias empresas brasileiras. Revista Eletrônica de Administração REAd, Edição Especial 58, v. 13, n. 4, dezembro, 2007. Disponível em: <http://www.seer.ufrgs.br/ index.php/read/article/viewFile/14319/8232>.

Imparato, Nicholas \& Hararl, Oren. A grande virada: inovação e escolha estratégica em uma era de transição. Rio de Janeiro: Campus, 1997.

Khoury, Grace \& Analou, Farhad. How palestinian managers cope with stress. The Journal of Management Development, v. 29, n. 3, p. 282-291, 2010. Disponível em: <http://search.proquest.com/ docview/216357649? accountid=34749>. Acesso em: 16 de abril de 2011.

Levy, Alberto R. Competitividade organizacional. São Paulo: Makron, McGraw-Hill, 1992.

Mendes, Paule Jeanne Vieira. Flexibilidade organizacional análise de uma experiência de organização e divisão do trabalho por processo em ambiente de P\&D. 2002. Dissertação (Mestrado) - Universidade Estadual de Campinas. Campinas: Unicamp. 


\section{REFERÊNCIAS}

Mintzberg, Henry. Criando organizações eficazes: estruturas em cinco configurações. São Paulo: Atlas, 2009.

Morgan, Gareth. Imagens da organização: edição executiva. 2. ed. São Paulo: Atlas, 2007.

PereiRA, Dejenane Aparecida Pascoal \& Amaral, Vera Lúcia Adami Raposo do. Escala de avaliação de depressão para crianças: um estudo de validação. Revista Estudos de Psicologia, v. 21, n. 1, p. 5-23, Campinas, janeiro/abril, 2004.

Pereira, Fernando Augusto; Forno, Ana Julia Dal \& TuBINo, Dalvio Ferrari. A flexibilidade no contexto do desenvolvimento de fábricas inteligentes. Produção Online -Revista Eletrônica de Engenharia de Produção, v. 8, n. 2, Florianópolis, julho, 2008. Disponível em: <http://producaoonline.org.br/ index.php/rpo/article/view/120>.

Pereira, Júlio Cesar R. Análise de dados qualitativos: estratégias metodológicas para ciências da saúde, humanas e sociais. 3. ed. São Paulo: Edusp. 2001.

Phillips, Paul \& Wright, Claire. E-business's impact on organizational flexibility. Journal of Business Research, v. 62, n. 11, p. 1.071-1.080, November, 2009.

Porter, Michel E. Estratégia competitiva: técnicas para análise de indústrias e da concorrência. 2. ed. Rio de Janeiro: Elsevier, 2004.

Santos, Cássia da Silva; Cerchiari, Ednéia Albino Nunes; Alvarenga, Márcia Regina Martins; Faccenda, Odival \& Olivelra, Maria Amélia de Campos. Avaliação da confiabilidade do miniexame do estado mental em idosos e associação com variáveis sociodemográficas. Cogitare Enfermagem, v. 15, n. 3, p. 406-412, Curitiba, julho/setembro, 2010.

Santos, Lucas Maia dos; Ferreira, Marco Aurélio Marques \& FARIA, Evandro Rodrigues de. Gestão financeira de curto prazo: características, instrumentos e práticas adotadas por micro e pequenas empresas. Revista de Administração da Unimep, v. 7, n. 3, p. 70-92, Piracicaba, setembro/dezembro, 2009.

Sennett, Richard. A corrosão do caráter. 14. ed. Rio de Janeiro: Record, 2009.
Serviço Brasileiro de Apoio às Micro e Pequenas Empresas - Sebrae. Boletim estatístico de micro e pequenas empresas. Brasília: Sebrae, 2005. Disponível em: <http://201.2.114.147/bds/BDS.nsf/03DE0485 DB219CDE0325701B004CBD01/\$File/NT000 A8E66.pdf> e <http://www.sebrae.com.br/ customizado/sebrae/integra_bia?ident_ unico=1129>. Acesso em: 07 de junho de 2010.

Serviço Brasileiro de Apoio às Micro e Pequenas Empresas de São Paulo - Sebrae/SP. 10 anos de monitoramento da sobrevivência e mortalidade de empresas. São Paulo: Sebrae-SP, 2008. Disponível em: <http://www. sebraesp.com.br/TenhoUmaEmpresa/Biblioteca/ OutrosConteudos/EstudosEPesquisas/Mortalidade DasEmpresas/Paginas/Mortalidade DasEmpresas. aspx\#bottom>. Acesso em: 19 de julho de 2010.

Silva, Carlos Alberto Vicente da. Redes de cooperação de micro e pequenas empresas: um estudo das atividades de logística no setor metalúrgico de Sertãozinho - SP. 2004. 199f. Dissertação (Mestrado em Engenharia de Produção) - Escola de Engenharia de São Carlos da Universidade de São Paulo. São Carlos: EESC/USP.

Slack, Nigel; Chambers, Stuart \& Johnston, Robert. Administração da produção. 3. ed. São Paulo: Atlas, 2009.

Souza Neto, Arlindo Lopes de. As micro, pequenas empresas no Mercosul e na União Europeia: os casos do Brasil e da Itália. 2006. 151p. Dissertação (Mestrado em Relações Internacionaius) - Instituto de Filosofia e Ciências Humanas da Universidade Federal do Rio Grande do Sul. Porto Alegre: UFRGS.

TACHIZAWA, Takesky \& Scalco, Oswaldo. Organização flexível: qualidade da gestão por processos. 2. ed. São Paulo: Atlas, 2006.

TenÓRIO, Fernando Guilherme. Flexibilização organizacional, mito ou realidade? Rio de Janeiro: FGV, 2002.

VAn MarReWIJK, Marcel. Strategic orientations: multiple ways for implementing sustainable performance. Technology and Investment, v. 1, n. 2, p. 85-96, May, 2010. Disponível em: <http://www.doaj.org/ 


\section{REFERÊNCIAS}

doaj?func=abstract\&id=789379>. Acesso em: 7 de janeiro de 2011.

VIEIRA, Flávia Regina Czarneski. Dimensões para o diagnóstico de uma gestão estratégica voltada para o ambiente de empresas de pequeno porte. 2002. Tese (Doutorado em Engenharia de Produção) Programa de Pós-Graduação em Engenharia de
Produção da Universidade Federal de Santa Catarina. Florianópolis: UFSC.

Wright, D. Brad. Care in the Country: a historical case study of long-term sustainability in 4 rural health centers. American Journal of Public Health, v. 99, n. 9 p. 1.612-1.618, September, 2009. 